IP Periodica Polytechnica

Transportation Engineering

47(2), pp. 157-165, 2019

https://doi.org/10.3311/PPtr. 10342

Creative Commons Attribution (i)

RESEARCH ARTICLE

\section{Tunnel/Predictor Display for Trajectory Control in Hypersonic Flight}

\author{
Csaba Moravszki ${ }^{1}$, József Rohács ${ }^{1 *}$, Gottfried Sachs ${ }^{2}$
}

Received 30 November 2016; accepted 20 February 2018

\begin{abstract}
A tunnel/predictor display which presents guidance information in a 3-dimensional format is considered for improving trajectory control in hypersonic flight. The displayed 3-dimensional information comprises a tunnel image and a predictor for indicating the aircraft position at a specified time ahead. The 3-dimensional guidance information is introduced to support the pilot in controlling the flight path. It is considered that piloting problems can be avoided which exist with conventional trajectory control techniques due to path-attitude decoupling. A predictor control law is constructed which yields controlled element properties (predictor-aircraft system) requiring minimum pilot compensation. This predictor control law forms the basis of the trajectory control improvement goal. Results from hypersonic flight simulation tests at the NASA Dryden Flight Research Center are presented for experimental verification. This paper is an outcome of a joint research effort of the NASA Dryden Flight Research Center, and the Institute of Flight Mechanics and Flight Control of the Technische Universität München and the Department of Aeronautics, Naval Architecture and Railway Vehicles (former Department of Aircraft and Ships at the Budapest University of Technology and Economics.
\end{abstract}

\section{Keywords}

Hypersonic flight, tunnel display, predictor, pilot model

\footnotetext{
${ }^{1}$ Department of Aeronautics, Naval Architecture and Railway Vehicles, Faculty of Transportation Engineering and Vehicle Engineering, Budapest University of Technology and Economics, H-1521 Budapest, P.O.B. 91, Hungary

${ }^{2}$ Institute of Flight System Dynamics,

Technische Universitiät München,

D-85747, Garching, Boltzmannstr. 15, Germany

*Corresponding author, e-mail: jrohacs@vrht.bme.hu
}

\section{Introduction}

Aircraft in hypersonic flight show unique dynamics and control properties when compared with vehicles in the conventional speed regime. A critical issue is trajectory control for which the correlation between flight path and pitch attitude changes following a pitch control input is of significant concern. For conventional aircraft, there is usually a wellbalanced correspondence between path and attitude responses which may be qualified as path-attitude consonance or pathattitude coupling. In hypersonic flight, the flight path lag can be as large as 25 seconds or more. Such a characteristic which causes significant problems in trajectory control is qualified as path-attitude decoupling. The addressed control problem is an issue of continuous interest and subject of recent research (Cox and Jackson, 1997; Meyers et al., 1995).

A novel type of cockpit display is considered for improving trajectory control, presenting guidance information in a 3-dimensional format to the pilot (e.g. Sachs, 2008; Moravszki and Sachs, 2008). This display type which is illustrated in Fig. 1 provides the pilot with guidance information which comprises a tunnel image and a predictor for indicating the aircraft position at a specified time ahead. Thus, it displays status and command information not only for the current situation but also for the future. Existing experience with 3-dimensional displays is concerned with the conventional speed regime where they show great promise for improving trajectory control.

The major novelty of the discussing method is included in synthesis of tunnel/predictor and trajectory prediction. The method was developed by the Technische Universität München (e.g. Sachs, 2008; Moravszki and Sachs, 2008; Sachs and Moravszki, 2002; 2006). Since that, the principles haven been applied widely in other solutions (for example: Sachs et al., 2008; Sachs and Holzapfel, 2008). The Budapest University of Technology and Economics developed its flight simulator (Korody, 2007) with support of the Technische Universität München had cooperating in display developments (Hermle et al., 1998; Moravszki et al., 2000) and the transferred knowledge had been utilized in other projects as conflict resolution precision landing control and active displays for operators (Rohacs and 
Jankovics, 2012; Rohacs, Voskuijl, and Siepenkotter, 2014; Rohacs, Rohacs and Jankovics, 2016). The delay in operator action had been investigated, too, in different applications (Pokoradi, 2008; Szabolcsi, 2008, Nagy and Jankovics, 2012). The displaying the predicted flight trajectories have interest in up-to-date studies, too (see for example Arent et al., 2011; Shish et al, 2015; or Горбунов, Нечаев, 2015).

The purpose of this paper is to consider the applicability of displays presenting guidance information in a 3-dimensional format for improving trajectory control in hypersonic flight. Particular emphasis is placed on developing a predictor control law which is appropriate for this high speed flight region.

This paper is an outcome of a joint research effort of the NASA Dryden Flight Research Centre, the Institute of Flight System Dynamics of the Technische Universität München and the cooperating Department of Aeronautics, Naval Architecture and Railway Vehicles (former department of Aircraft and Ships) at the Budapest University of Technology and Economics and on flight path control problems of aerospace craft in the hypersonic speed regime.

\section{Tunnel/Predictor Display}

Basically, a display presenting 3-dimensional guidance information shows the command trajectory, e.g. in the form of a tunnel, and the position of the aircraft at a specified time ahead (prediction time) with the use of a predictor, Fig. 1. The predictor position referenced to a specially marked cross section frame of the tunnel provides the pilot with a precise indication of the flight path error at the prediction time. The pilot can act in response to the displayed predictor position error for controlling the trajectory.

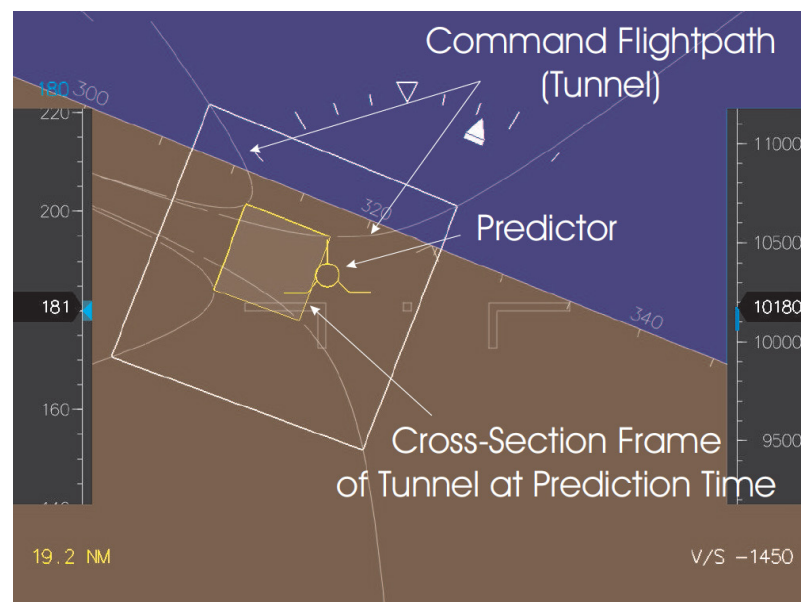

Fig. 1 Display presenting guidance information in 3-dimensional format

There are two main goals of the predictor:

1. Aircraft position indication at the prediction time ahead. This may be qualified as a face validity issue.

2. Achieving a controlled element (predictor-aircraft system) requiring minimum pilot compensation. This may be qualified as a manual control issue.
For achieving goal 1, a model is required for describing the continuation of the trajectory. Such a model is based on geometric and kinematic relationships which describe the trajectory continuation, as illustrated in Fig. 2. Using these relationships, the displacement of the predicted position from the command trajectory at the prediction time ahead can be expressed as

$$
\Delta h_{P R}(t)=\Delta h(t)-h_{C}^{*}+K_{\gamma} \Delta \gamma(t)+K_{\dot{\gamma}} \Delta \dot{\gamma}(t)
$$

where

$$
h_{P R}(t)=h\left(t+T_{P R}\right)
$$

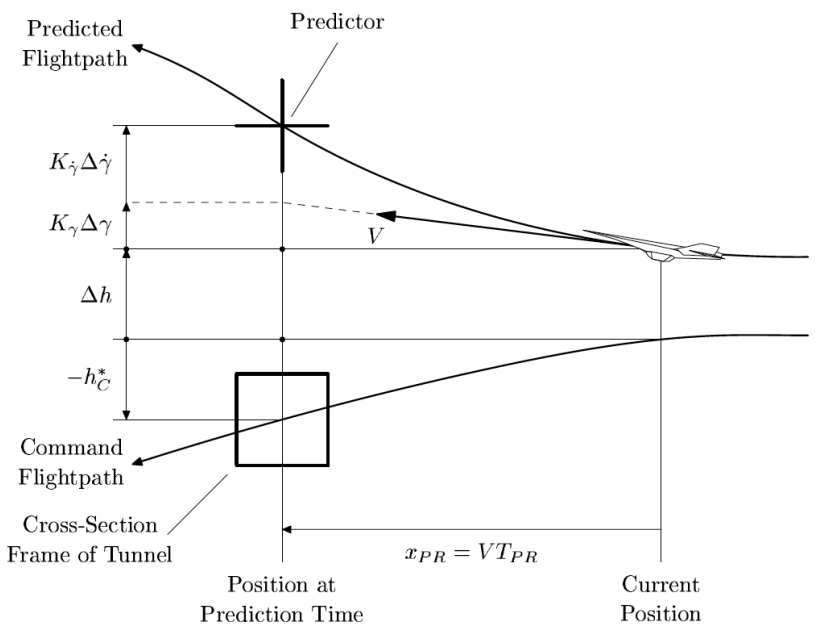

Fig. 2 Model for describing flight path continuation

Considering that the change of the flight path angle, $\Delta \gamma$, remains during the prediction time within the magnitude, where the small angle approximation holds, $K_{\gamma}$ can be replaced by

$$
K_{\gamma} \approx V T_{P R}
$$

The displacement of the predictor position can be described with quantities of the current aircraft state, as graphically illustrated with the block diagram and related pathways in Fig. 3. These quantities, which are available from sensor measurements on board of the aircraft, can be used for constructing the predictor control law. The term $h_{C}{ }^{*}$, the commanded altitude, calculated during the mission planning phase and presented by the tunnel on the display, remains constant in point of view of the aircraft future movements. The following relation for the predictor displacement referenced to flight path angle rate holds after Laplace transformation

$$
\Delta h_{P R}(s)=\left[K_{\dot{\gamma}}+\frac{V T_{P R}}{s}+\frac{V}{s^{2}}\right] \Delta \dot{\gamma}(s) .
$$

The displacement $\Delta h_{P R}$ is indicated by the predictor symbol in the tunnel/predictor display as an error $e_{P R}$. Both quantities are related to each other according to (as also shown in the block diagram of Fig. 3): 


$$
e_{P R}(s)=K_{P R} \Delta h_{P R}(s) \text {. }
$$

With the use of Eqs. (3) and (4), the transfer function between the flight path angle rate and the error presented by the predictor symbol reads

$$
Y_{P R}(s)=\frac{e_{P R}(s)}{s \Delta \gamma(s)}=K_{P R} V \frac{\left(K_{\dot{\gamma}} / V\right) s^{2}+T_{P R} s+1}{s^{2}} .
$$

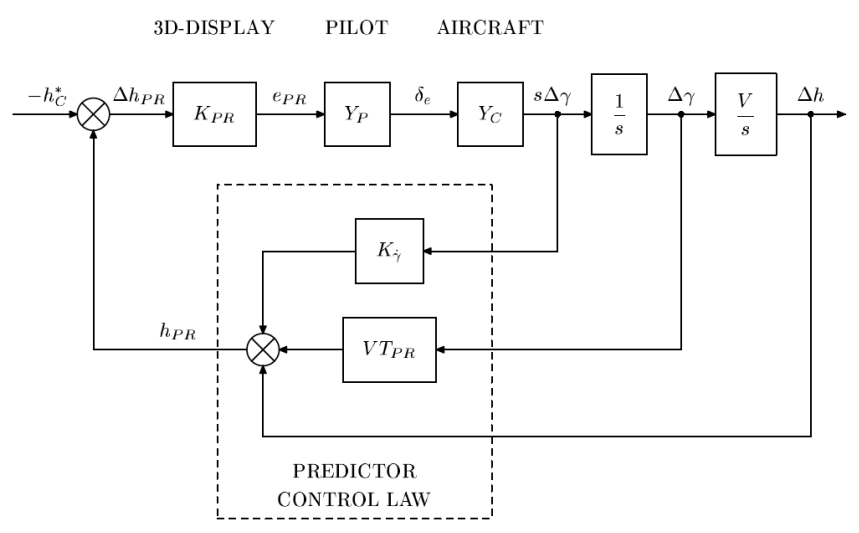

Fig. 3 Block diagram for predictor control law

Goal 2 can be achieved if the predictor-aircraft system, $Y_{P R}(s) Y_{C}(s)$, has a $K / s$ characteristic centred around pilot-system crossover (Hess, 1997; McRuer, 1988). Accordingly

$$
Y_{P R}(s) Y_{C}(s)=\frac{K}{s}
$$

For developing an appropriate predictor control law achieving this goal, the transfer function of the aircraft valid for hypersonic flight, $Y_{C}(s)$, has to be determined. This will be done in the subsequent section, accounting for the specific properties of hypersonic flight dynamics.

\section{Hypersonic Flight Dynamics}

For a rather general treatment of the trajectory control problem in hypersonic flight, analytical expressions for the transfer function in mind are developed. To be able to use the linearized equations of motion for longitudinal flight at hypersonic speed, typical stationary fight conditions were selected as basis for further analysis.

The trajectory of the flight path was selected over the Equator at a constant altitude of $100,000 \mathrm{ft}$ with the speed of $10 \mathrm{Mach}$. The system at these flight conditions exert significant properties of hypersonic flight, which can be ignored in the conventional speed regime (Sachs, 1976).

The dynamics and response properties which are of concern for the control problem in mind are the eigenvalues of the aircraft and the transfer characteristics between flight path angle rate and pitch control input.
As regards the eigenvalues, there are three modes of motion (as opposed to two modes in the conventional speed regime) due to the effects of altitude dependent forces and moments, yielding:

1. short period mode $\left(\omega_{S P}, \zeta_{S P}\right)$

2. phugoid $\left(\omega_{P}, \zeta_{P}\right)$

3. height mode $\left(s_{h}\right)$

The short period mode eigenvalue which depends on stability derivatives in a similar way as in the conventional speed regime can be expressed as

$$
\begin{aligned}
& \omega_{S P} \approx \sqrt{M_{q} Z_{\omega}-M_{\alpha}} \\
& 2 \omega_{S P} \zeta_{S P} \approx-\left(Z_{\omega}+M_{q}+M_{\alpha}\right) .
\end{aligned}
$$

The phugoid shows unique characteristics in hypersonic flight because of the effects of altitude dependent forces and moments on aircraft dynamics. It may be described by (for $M_{u}=0$ and $\left.M_{h}=0\right)$, (Sachs, 1976):

$$
\begin{aligned}
& \omega_{P} \approx \sqrt{-g \rho_{h}} \\
& \zeta_{P} \approx 0 .
\end{aligned}
$$

The height mode which is not existent in the conventional speed regime or can be neglected is due to the effects of altitude dependent forces and moments. It is an aperiodic mode of motion and describes long-term characteristics of the aircraft. This low frequency eigenvalue may be expressed as (for $M_{u}=0$ and $\left.M_{h}=0\right)$, (Sachs, 1976):

$$
s_{h} \approx X_{u}-\frac{Z_{u}}{Z_{h}} X_{h} .
$$

A typical example is presented in Fig. 4 which provides an insight into the magnitude of the eigenvalues of vehicles at hypersonic speed. Corresponding to the numerical values illustrated in Fig. 4, the following relation can be regarded as generally valid:

$$
\left|s_{h}\right|<<\omega_{P}<<\omega_{S P}
$$

The transfer function between flight path angle rate and pitch control input reads

$$
\begin{aligned}
& Y_{C}(s)=\frac{s \Delta \gamma(s)}{\delta_{e}(s)}= \\
& -\frac{\left(Z_{\delta_{e}} / V\right) s^{2}\left(s+1 / T_{h 1}\right)\left(s+1 / T_{h 2}\right)\left(s+1 / T_{h 3}\right)}{\left(s^{2}+2 \zeta_{S P} \omega_{S P} s+\omega_{S P}^{2}\right)\left(s^{2}+2 \zeta_{P} \omega_{P} s+\omega_{P}^{2}\right)\left(s-s_{h}\right)}
\end{aligned}
$$

where the numerator zeros are given by

$$
\begin{aligned}
& \frac{1}{T_{h 1}} \approx-X_{u}+\left(X_{\alpha}-g\right) \frac{Z_{u}}{Z_{\alpha}} \\
& \frac{1}{T_{h 2}} \approx-\frac{1}{T_{h 3}} \approx \sqrt{\frac{Z_{\alpha} M_{\delta_{e}}}{Z_{\delta_{e}}}-M_{\alpha}} .
\end{aligned}
$$



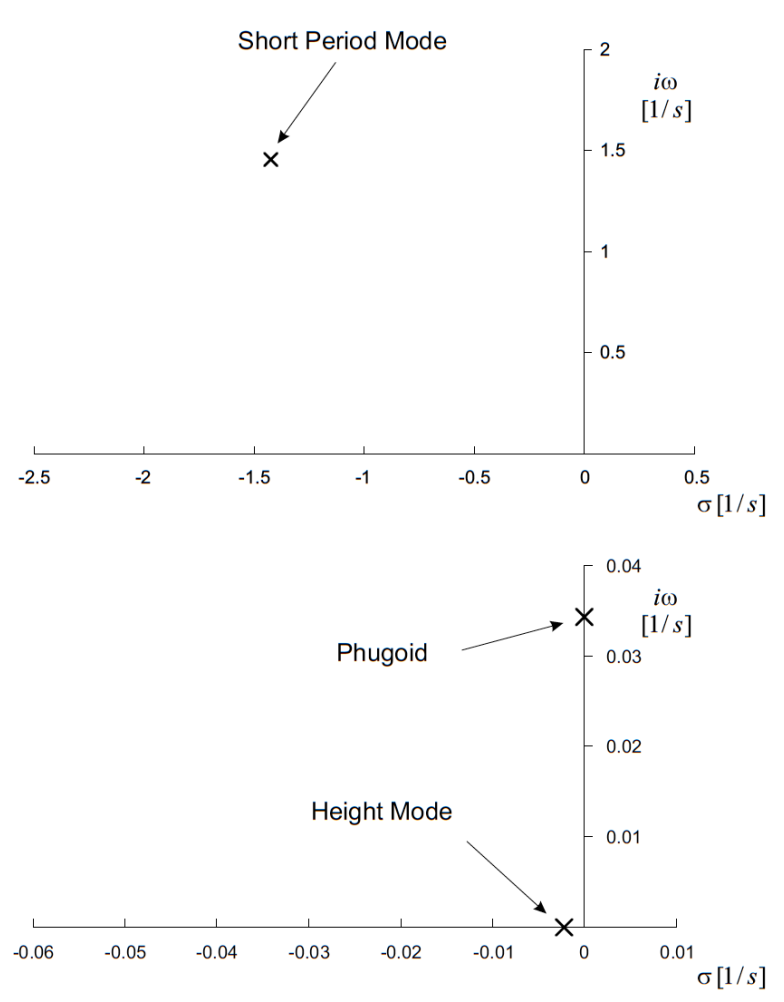

Fig. 4 Eigenvalues of vehicle in hypersonic flight $(\mathrm{M}=10, \mathrm{~h}=100,000 \mathrm{ft})$

The larger numerator zeros, $1 / T_{h 2}$ and $1 / T_{h 3}$ can be ignored. This is because they are related to a frequency region which is greater than $\omega_{S P}$ and, thus, are not of concern for the problem in mind. Accordingly, the transfer function between flight path angle rate and pitch control input may be rewritten as

$$
\begin{aligned}
& Y_{C}(s)=\frac{s \Delta \gamma(s)}{\delta_{e}(s)}= \\
& -\frac{Z_{\omega} M_{\delta_{e}} s^{2}\left(s+1 / T_{h 1}\right)}{\left(s^{2}+2 \zeta_{S P} \omega_{S P} s+\omega_{S P}^{2}\right)\left(s^{2}+2 \zeta_{P} \omega_{P} s+\omega_{P}^{2}\right)\left(s-s_{h}\right)}
\end{aligned}
$$

\section{Pilot-Predictor-Aircraft System}

Using the relations given by Eqs. (4) and (12), the openloop predictor-aircraft system which represents the controlled element can be expressed as

$$
\begin{aligned}
& Y_{P R}(s) Y_{C}(s)= \\
& -\frac{K_{P R} K_{\dot{\gamma}} Z_{\omega} M_{\delta_{e}}\left[s^{2}+\left(V T_{P R} / K_{\dot{\gamma}}\right) s+V / K_{\dot{\gamma}}\right]\left(s+1 / T_{h 1}\right)}{\left(s^{2}+2 \zeta_{S P} \omega_{S P} s+\omega_{S P}^{2}\right)\left(s^{2}+2 \zeta_{P} \omega_{P} s+\omega_{P}^{2}\right)\left(s-s_{h}\right)} .
\end{aligned}
$$

The $K / s$ characteristics goal for the crossover frequency region can be achieved by an appropriate selection of the numerator zeros of Eq. (13). The bracketed term in the nominator of Eq. (13) may be rewritten to yield, with the use of its zeros $-1 / T_{1,2}$ :

$$
s^{2}+\frac{V T_{P R}}{K_{\dot{\gamma}}} s+\frac{V}{K_{\dot{\gamma}}}=\left(s+\frac{1}{T_{1}}\right)\left(s+\frac{1}{T_{2}}\right) .
$$

The frequency response properties of the predictor-aircraft system are illustrated in Fig. 5, showing the effect of the addressed zeros. Placing one zero, $-1 / T_{2}$, close to the short period frequency determines the upper end of the $K / s$ frequency region. The other zero, $-1 / T_{1}$, at the lower end, may be selected such that a sufficiently large $K / s$ frequency region is achieved. Correspondingly, the $K / s$ frequency region is given by

$$
\frac{1}{T_{1}} \leq \omega \leq \frac{1}{T_{2}}
$$

where

$$
T_{2} \approx \frac{1}{\omega_{S P}}
$$

For achieving the described $K / s$ frequency region characteristics, the predictor control law quantities (i.e. the prediction time $T_{P R}$ and the gain $K_{\dot{\gamma}}$ ) may be selected as

$$
\begin{aligned}
& T_{P R} \approx T_{1} \\
& K_{\dot{\gamma}} \approx \frac{V T_{P R}}{\omega_{S P}} .
\end{aligned}
$$

Closed-loop properties of the pilot-predictor-aircraft system can be evaluated using a pilot model valid for a controlled element with $\mathrm{K} / \mathrm{s}$ characteristics. According to (Hess, 1997; McRuer, 1988), the following pilot model holds for this, multichannel compensation case, which can be linearized using the Padé approximation (Szabolcsi, 2007):

$$
Y_{P}(s)=K_{P} e^{-\tau_{e} s} \approx K_{P} \frac{1-s \tau}{1+s \tau}
$$

A primary issue of closed-loop properties concerns stability and mode characteristics which can be evaluated using the root locus technique. This technique yields results of a rather general nature, as graphically illustrated in Fig. 6. Basically, there are three root locus branches. One branch emerges from the openloop short period poles (closed-loop attitude mode), one from the open-loop phugoid poles (closed-loop path mode) and one from the origin (closed-loop aperiodic mode). The closed-loop path mode which is related to the predictor numerator zeros -1 / $T_{1,2}$ shows a stable behaviour for all pilot gain values. Increasing the pilot gain yields a faster response (larger frequency) and a higher damping, contributing to an improvement of trajectory control. The closed-loop aperiodic mode is stable provided the numerator zero of the altitude-elevator transfer function, $-1 / T_{h 1}$, is in the left half plane. The closed-loop attitude mode shows some destabilization. The theoretical findings were subject of an experimental verification with pilot-in-the-loop simulations. This simulation experiments were also concerned with determining a prediction time value adequate for hypersonic flight. Results are presented in a subsequent section. 

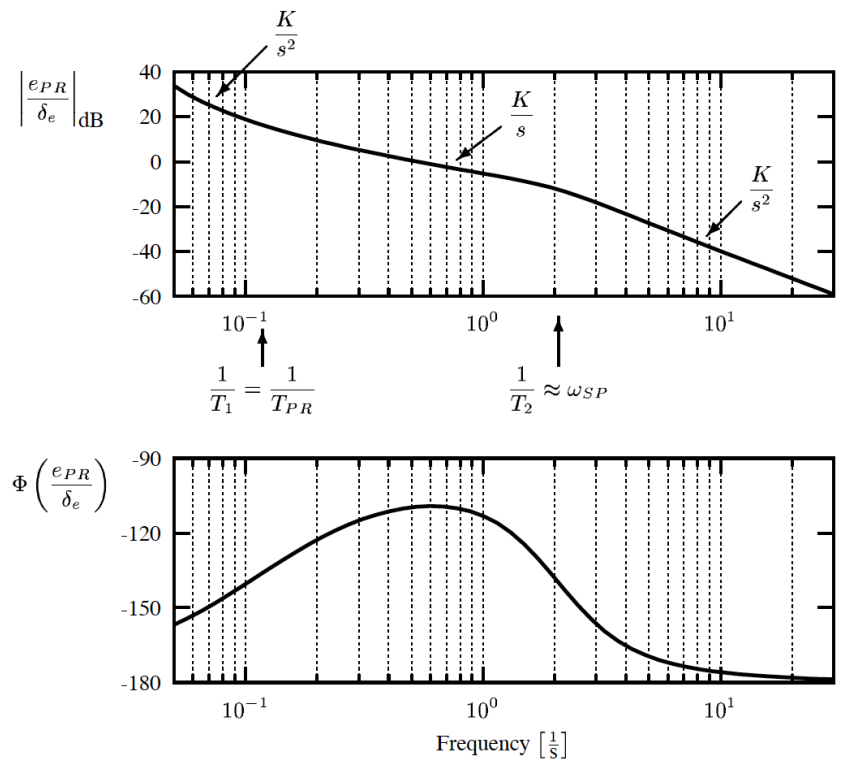

Fig. $5 \mathrm{~K} / \mathrm{s}$ frequency response characteristics of predictor-aircraft system in hypersonic flight $\left(\mathrm{T}_{\mathrm{PR}}=8.5 \mathrm{~s}, \mathrm{M}=10, \mathrm{~h}=100,000 \mathrm{ft}\right)$

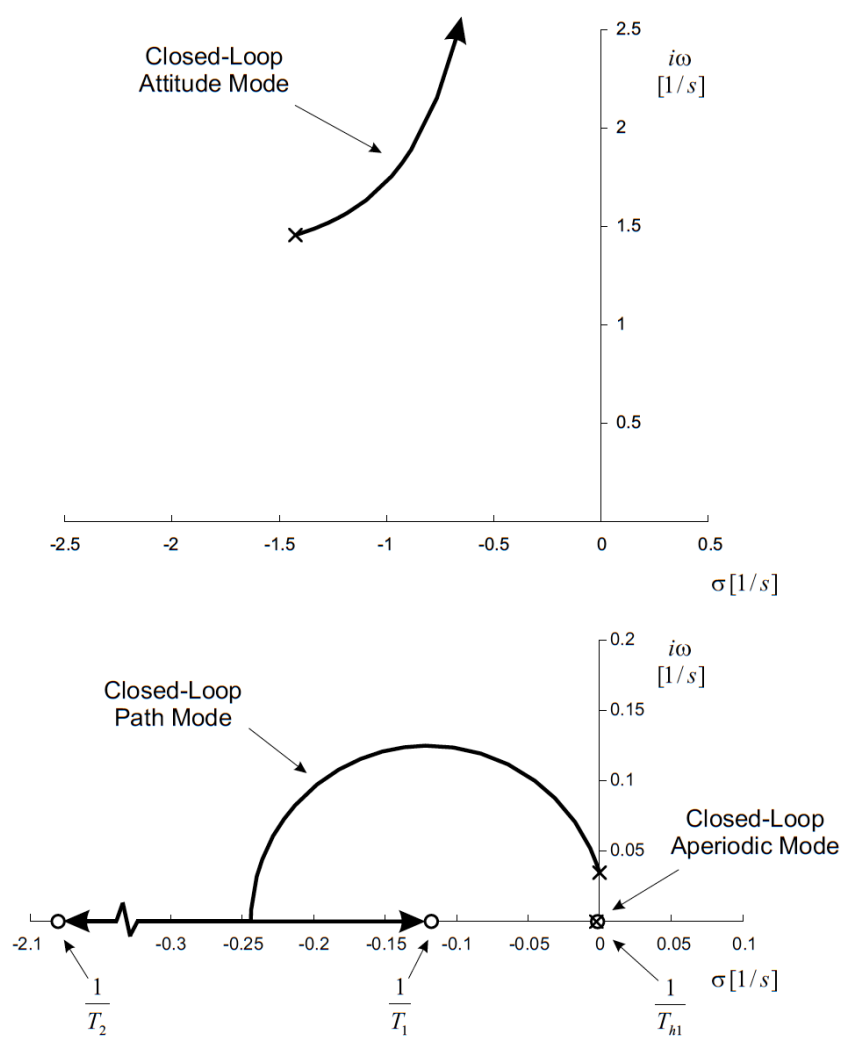

Fig. 6 Root locus diagram of pilot-predictor-aircraft system in hypersonic flight $\left(\mathrm{T}_{\mathrm{PR}}=8.5 \mathrm{~s}, \mathrm{M}=10, \mathrm{~h}=100,000 \mathrm{ft}\right)$

\section{Simulator Facility}

Simulation experiments were performed using a high speed flight simulator facility of the NASA Dryden Flight Research Center, Edwards, California, USA. The simulation experiments were part of joint research effort with the NASA Dryden Flight Research Center on dynamics and flying qualities of hypersonic aircraft.
The high speed flight simulator which is used in civil transport research and X- 33 programs features a fixed base cockpit with two seats, three monitors for flight and navigation instruments and a projection system for an out-the-window view or for simulating a head up display (Fig. 7). The controls configuration at the left pilot seat which was used in the simulation experiments comprises a stick and rudder pedals. The controls for the right seat are a sidestick and rudder pedals. The stick control force is electrically generated. To the left side of each pilot seat are four throttles from which the right one was used. The instrument panel basically corresponds to the Space Shuttle instrumentation, consisting of a central attitude director indicator and linear scale indications of angle of attack, horizontal acceleration, Mach number, equivalent airspeed, vertical acceleration and speed as well as barometric and radar altitude. Other instruments show radar altitude, heading, load factor and dynamic pressure.

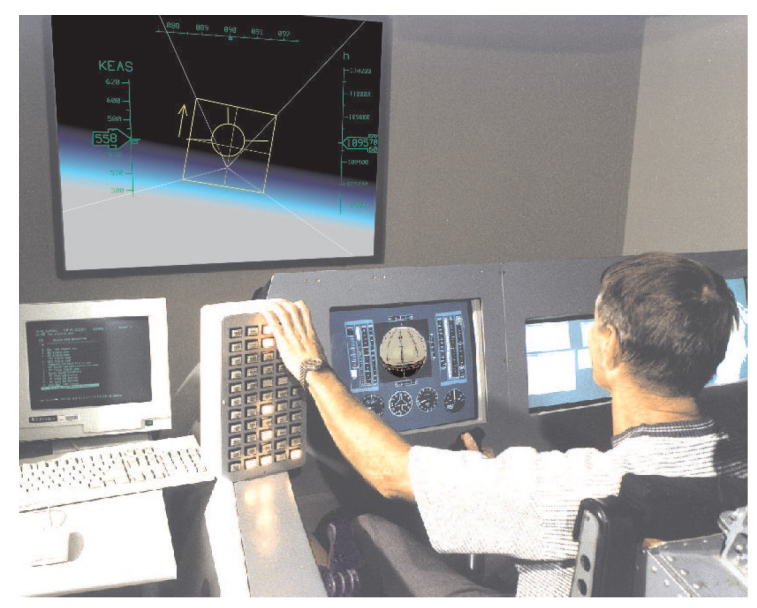

Fig. 7 Flight simulator of NASA Dryden Flight Research Center

For the flight path control simulation experiments, the tunnel/ predictor display configuration shown in Fig. 8 was used for presenting guidance information in a 3-dimensional format. The centre of the specially marked cross-section frame of the tunnel at the prediction time ahead is indicated in order to provide the pilot with a precise reference for the predictor position. The control task of the pilot is to correct the errors in the predicted position and to hold the predictor symbol as close as possible to the centre of the reference cross-section frame of the tunnel. The tunnel/predictor display was presented to the pilot in the form of a head up display (as shown in Fig. 7). For simulating aircraft dynamics in hypersonic flight, the Generic Hypersonic Aerothermodynamic Model Example GHAME (Bowers, 1989) was applied. It describes the dynamics of a single-stage-toorbit aerospace plane, based on a six-degree-of-freedom flight mechanics model. The aerothermodynamics data set covers a range from Mach 0 to 25. Powerplant characteristics correspond to a turbo-ram-scramjet-engine combination.

With regard to properties of the atmosphere, standard atmospheric conditions as well as disturbed conditions were applied. The disturbances from standard conditions were 
modelled according to observations made with the Space Shuttle (Blanchard, 1989). The disturbances concern density perturbations which were applied in the form of a (1-cos) characteristic, with a duration of 20 seconds and a magnitude of $2.5 \%$ of the standard value. The sign and time interval of the disturbances were selected using a random function.

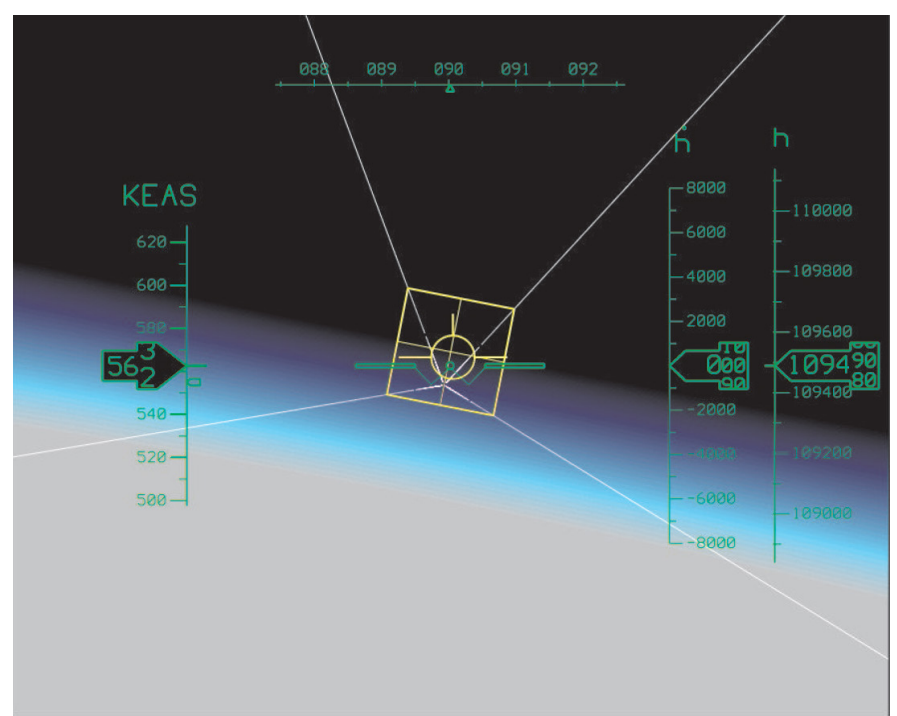

Fig. 8 Tunnel/predictor display used in simulation experiments at NASA Dryden Flight Research Center

\section{Simulation Experiments Results}

For the experimental program, control tasks were selected which are considered to be of concern for maneuvers of hypersonic cruise vehicles (e.g. Berry, 1988):

1. vertical plane altitude change for reducing initial offset from the command trajectory

2. following command trajectory with one altitude change downwards

3. following command trajectory with double altitude changes (downwards/upwards combination)

Reference was made to values for adequate and desired pilot performance. Table 1 shows the values for maneuver 1 which is considered in the following.

Table 1 Controlled parameters and performance values for maneuver 1

\begin{tabular}{lcc}
\hline Controlled Parameters & Adequate Performance & Desired Performance \\
\hline Target Altitude & $\pm 600 \mathrm{ft}$ & $\pm 300 \mathrm{ft}$ \\
Trim Speed (EAS) & $\pm 10 \mathrm{kt}$ & $\pm 5 \mathrm{kt}$ \\
\hline
\end{tabular}

A test pilot of the NASA Dryden Flight Research Center conducted the simulation experiments. He has a large experience in high speed flight, including the YF-12 aircraft. This was of great value for the success of the investigation.

A basic issue of the simulation experiments was to show that the tunnel/predictor display is an appropriate and efficient means for supporting the pilot in controlling the trajectory. Results of a simulation run are presented in Fig. 9 which shows the time histories for the predictor and current positions as well as the control input. The time history of the predictor position shows only small deviations from the command value. As a result, the control goal has been achieved. This outcome is supported by pilot ratings which are in favour of the predictor concept as an efficient means for improving aircraft guidance and control.

The predictor, which originally concerns the control of the predicted position, is also an efficient means for controlling the current position of the aircraft. The results presented in Fig. 9 show that this objective is also achieved. As a result, the control of altitude is in accordance with the performance values given in Table 1 .

The prediction time $T_{P R}$ selected for the simulation run illustrated in Fig. 9 proved to be well suited for trajectory control at the high speed flight condition under consideration. Smaller $T_{P R}$ values yielded less effective control results, with larger deviations from the command trajectory and increased control activity. An example is presented in Fig. 10. Comparison with Fig. 9 shows that there are significant differences.
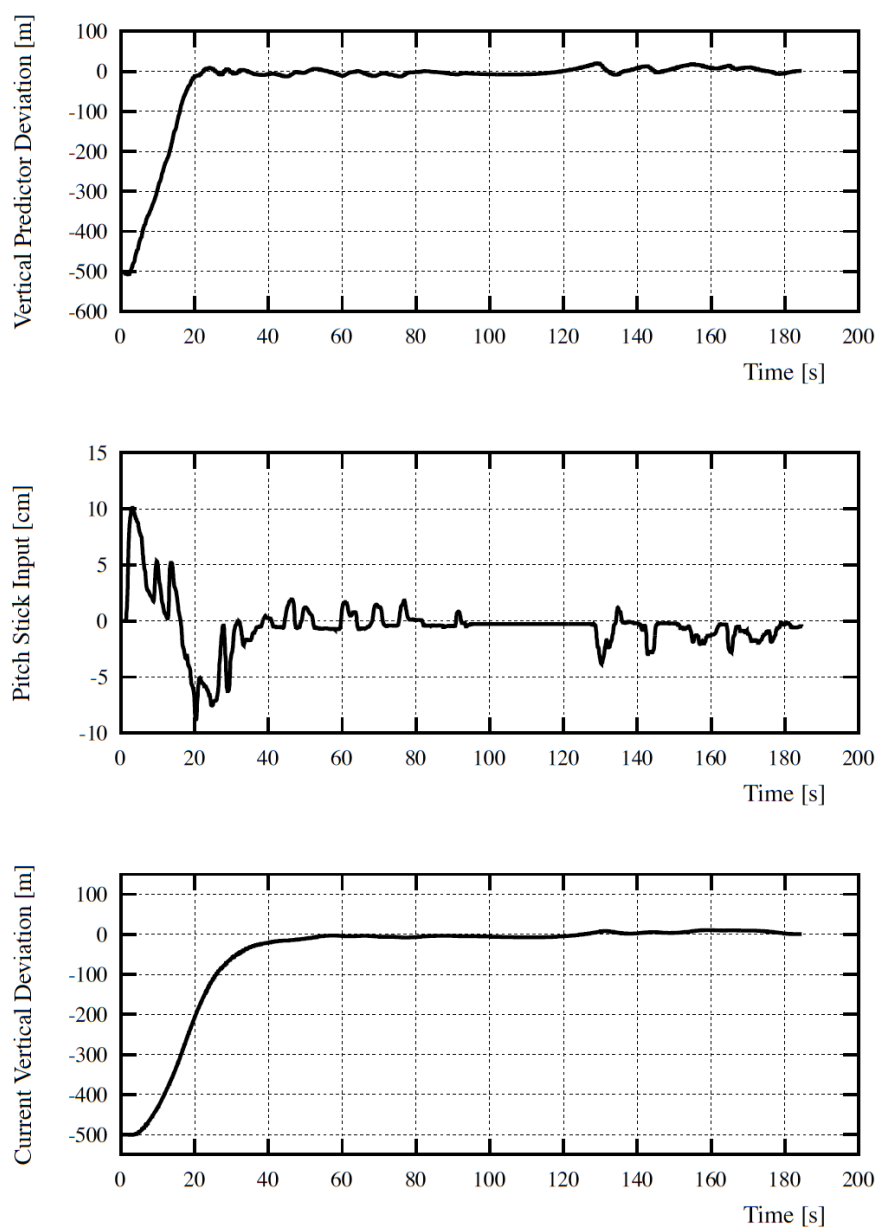

Fig. 9 Results from hypersonic simulation experiments with $\mathrm{T}_{\mathrm{PR}}=8.5 \mathrm{~s}$ $(\mathrm{M}=10, \mathrm{~h}=100,000 \mathrm{ft})$ 

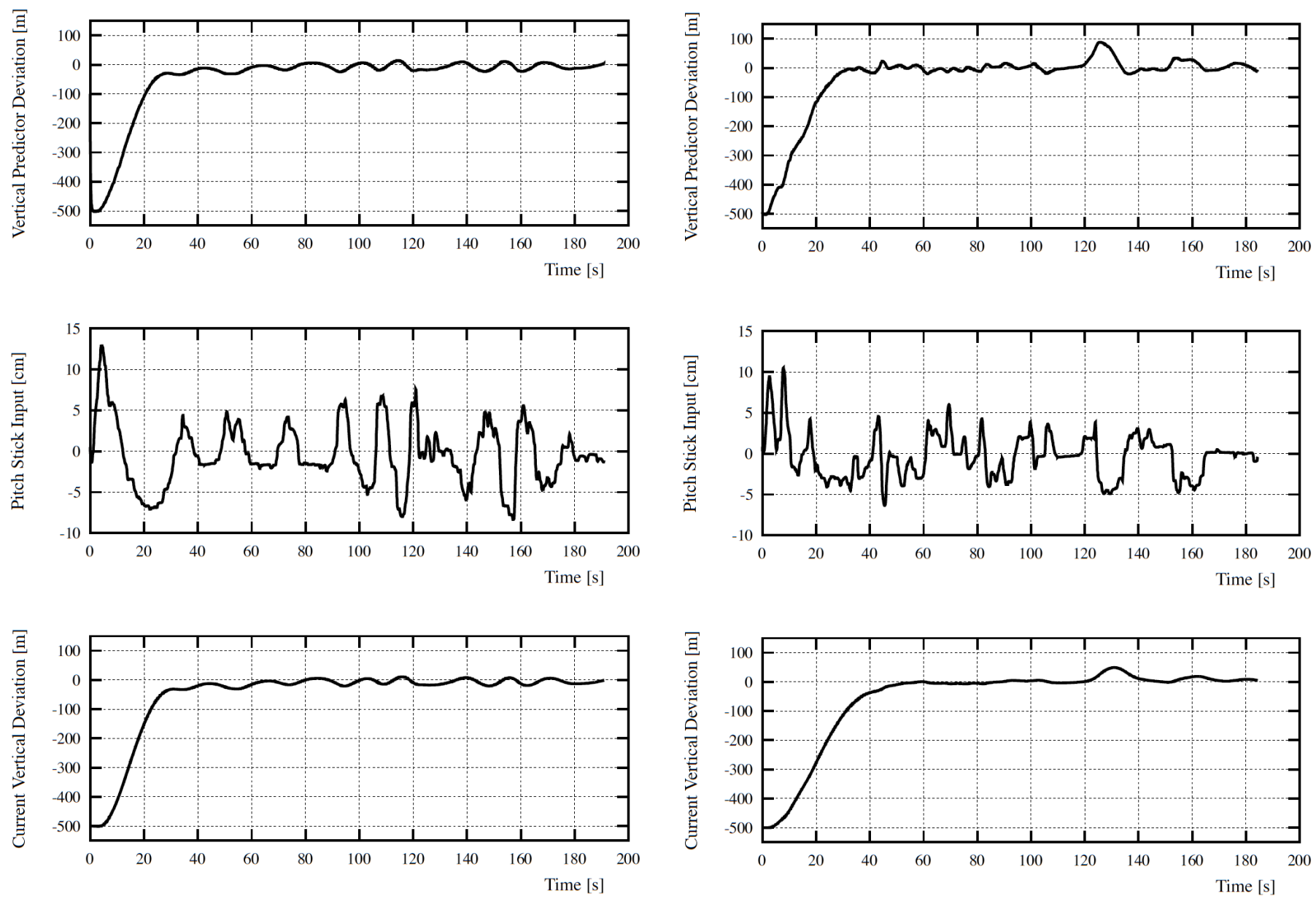

Fig. 10 Results from hypersonic simulation experiments with $T_{P R}=2.125 \mathrm{~s}$ $(\mathrm{M}=10, \mathrm{~h}=100,000 \mathrm{ft})$

Fig. 11 Effect of density perturbation on control performance and activity $\left(\mathrm{T}_{\mathrm{PR}}=8.5 \mathrm{~s}, \mathrm{M}=10, \mathrm{~h}=100,000 \mathrm{ft}\right)$

The effect of density perturbations described in a previous section is illustrated in Fig. 11. According to the disturbances acting in the aircraft, the control activity is greater than in the non-perturbed reference case (Fig. 9).

An example for speed control is given in Fig. 12 which shows the time histories for speed and throttle setting of a simulation run previously considered (Fig. 9). There are only minor deviations from the reference speed value. As a result, speed control could be accomplished in accordance with the performance values given in Table 1 .

Abasic issue for the experimental verification is the prediction time $T_{P R}$ which is a factor of primary concern for the predictor control law. This is because it has a substantial effect on the length of the $K / s$ frequency region and, thus, on compensatory control characteristics and related pilot performance. An evaluation of the effect of the prediction time $T_{P R}$ is given in Fig. 13 which presents results on control performance and activity. Small values of $T_{P R}$ yield larger deviations from the command trajectory and greater control activity. An improvement is due to increased $T_{P R}$ values leading to a more precise flight path control, with reduced control activity.
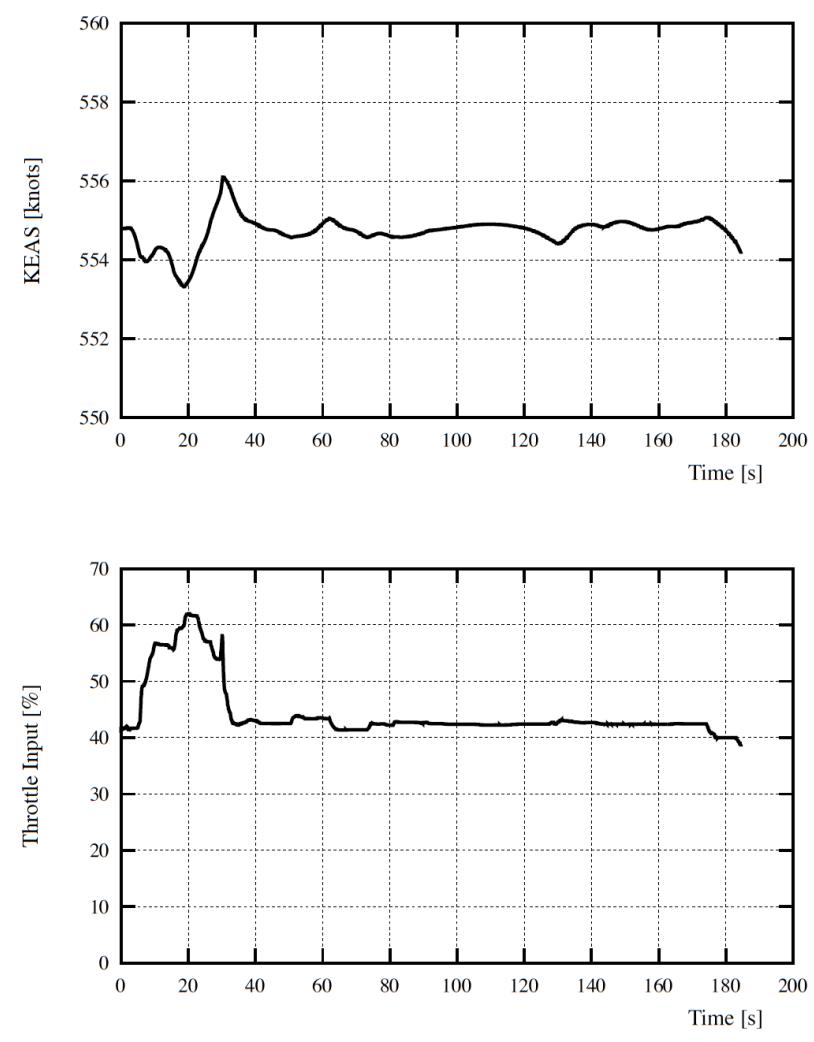

Fig. 12 Results of speed control $\left(T_{P R}=8.5 \mathrm{~s}, M=10, h=100,000 \mathrm{ft}\right)$ 

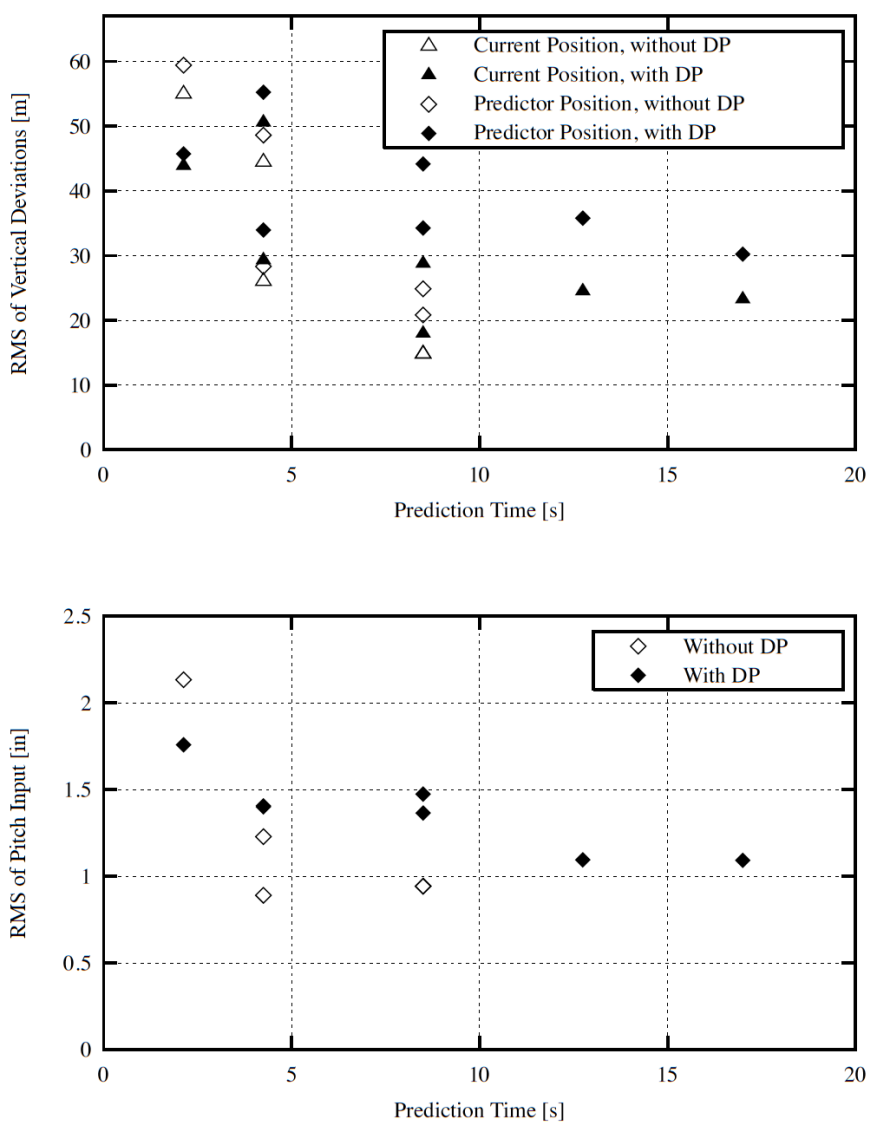

Fig. 13 Effect of prediction time on control performance and activity with and without Density Perturbation (DP) (M=10, h=100,000ft)

\section{Conclusions}

A display which comprises a tunnel image and a predictor in a 3-dimensional format is considered for improving trajectory control in hypersonic flight. The predictor display is integrated with the predictor window to provide an adequate performance margin for the pilot and a cross in the middle of it defining the commanded position. The predictor indicates the future position of the aircraft at a specified time ahead. The predictor has been combined with the for this flight condition designed tunnel providing the pilot the ability to 'see forward'. The displayed 3-dimensional guidance information is introduced as a means for supporting the pilot in flight path control. The control of the flight path is a critical issue of hypersonic aircraft dynamics when applying conventional control techniques. This concerns the correlation between flight path and pitch attitude changes following a pitch control input, yielding path-attitude decoupling in hypersonic flight.

A predictor control law is developed a primary goal of which is to minimize pilot effort while retaining maximum system performance. The predictor has been designed for one operation mode of hypersonic vehicle moving in the vertical plane. This predictor control law yields a $K / s$ characteristic of the controlled element over an adequately broad frequency region centered around pilot-predictor-aircraft crossover, as a design condition.
A list of parameters (predictor gain and the two time constants of the predictor) has been specified for predictor design in case of application to hypersonic flight. The smaller one of the two time constants should be placed close to the dominant short period pole. The optimum value of the prediction time has been allocated as $8.5 \mathrm{~s}$ at the given flight condition. Results from hypersonic flight simulation tests performed at a high speed flight simulator at the NASA Dryden Flight Research Center are presented for experimental verification.

\section{References}

Arents, R., Groeneweg, J., Borst, C., Van Paassen, M., Mulder, M. (2011). Predictive Landing Guidance in Synthetic Vision Displays. The Open Aerospace Engineering Journal. 4, pp. 11-25.

https://doi.org/10.2174/1874146001104010011

Berry, D. (1988). National aerospace plane flying qualities task definition study. Technical Report NASA Technical Memorandum 100452, NASA Dryden Flight Research Center, Edwards.

Blanchard, R., Hinson, E., Nicholson, J. (1989). Shuttle high resolution accelerometer package experiment results: Atmospheric density measurements between 60 and $160 \mathrm{~km}$. Journal of Spacecraft and Rockets. 26(3), pp. 173-180.

https://doi.org/10.2514/3.26050

Bowers, A., Noffz, G., Gonda, M., Iliff, K. (1989). A Generic Hypersonic Aerodynamic Model Example (GHAME). Technical report, NASA Dryden Flight Research Facility.

Cox, T. H., Jackson, D. W. (1997). Supersonic flying qualities experience using the SR-71. In: AIAA Atmospheric Flight Mechanics Conference Proceedings. pp. 496-508. https://doi.org/10.2514/6.1997-3654

Hess, R. A. (1997). Feedback control models - manual control and tracking. In: Handbook of Human Factors and Ergonomics. pp. 1249-1294. Wiley, New York, $2^{\text {nd }}$ edition.

Hermle, P., Moravszki, Cs., Sachs, G., Rohács, J. (1998). Aircraft Interactive Navigation Display Design Using Touchscreen Technique. In: Proceedings of the 6th Mini Conference on Vehicle System Dynamics, Identification and Anomalies. Budapest, pp. 393-401.

Korody, E. (2007). Development of Multifunctional, New Generation Flight Simulator and Examination of Different Control Systems Summary of Ph.D. Thesis. Budapest University of Technology and Ecopnomics, Budapest, (In Hungarian)

McRuer, D. T. (1988). Pilot modeling. In: AGARD-LS-157. pp. 2.11-2.30.

Moravszki, Cs., Rohács, J., Hermle, P., Sachs, G. (2000). Electronic Flight Display Development Supported by Commercial-off-the-Shelf Tools. In: 22th Congress of International Council of Aeronautical Science. Harrogate, UK, 2000, pp. 642.1-642.8.

http://www.icas.org/ICAS_ARCHIVE/ICAS2000/PAPERS/ICA0642.PDF Moravszki, C., Sachs, G. (2008). Predictive Flight Path Display for Hypersonic Trajectory Control Improvement. In: Proceedings of the 10th Mini Conference on Vehicle System Dynamics, Identification and Anomalies. Department of Railway Vehicles, Faculty of Transport Engineering, Budapest University of Technology and Economics, Ed. I. Zobory, pp. 487-494.

Myers, T. T., Klyde., D. H., McRuer, D. T., Suchomel, C. (1995). Influence of path-attitude lag in hypersonic flying qualities. In: 33rd Aerospace Sciences Meeting and Exhibit, Aerospace Sciences Meetings. https://doi.org/10.2514/6.1995-555 
Nagy, A., Jankovics, I. (2012). Measurement of Small Aircraft Pilot's Reaction Time Variation With Psychological Load in Flight Simulator "Proceedings of AIRTEC", Frankfurt am Main, Germany, pp. 1-10.

Pokorádi, L. (2008). Rendszerek és folyamatok modellezése. Campus Kiadó Debrecen. (in Hungarian)

Rohacs, D., Jankovics, I. (2012). Active Conflict Detection and Resolution Method for General Aviation. In: The 12th International Conference on Vehicle system Dynamics, Identification and Anomalies (VSDIA), BME Budapest pp. 385-392. Budapest, Hungary, Nov. 8-10, 2010,

Rohacs, D., Voskuijl, M., Siepenkotter, N. (2014). Evaluation of Landing Characteristics Achieved by Simulations and Flight Tests on a SmallScaled Model Related to Magnetically Levitated Advanced Take-Off and Landing Operations. In: Proceedings of the 29th Congress of the International Council of the Aeronautical Sciences (ICAS), 2014-09-01, pp. 1-10. St. Petersburg, Russia, Sept. 7-12, 2014.

http://www.icas.org/ICAS_ARCHIVE/ICAS2014/data/ papers/2014_0901_paper.pdf

Rohacs, J., Rohacs, D., Jankovics, I. (2016). Conceptual development of an advanced air traffic controller workstation based on objective workload monitoring and augmented reality. Proceedings of the Institution of Mechanical Engineers, Part G: Journal of Aerospace Engineering. 230(9), pp. 1747-1761. https://doi.org/10.1177/0954410016636154

Sachs, G. (1976). Längsstabilität im Überschall- und Hyperschallflug. Zeitschrift für Flugwissenschaften. 24(6), pp. 310-329. (in German)

Sachs, G. (2008). Predictor-tunnel display for precision flight path control. Mathematical Problems in Engineering Aerospace and Sciences, Vol. 2: Advances in Mathematical Problems in Engineering Aerospace and Sciences, Ed. S. Sivasundaram. Cambridge Scientific Publishers, pp. 221-234.

Sachs, G., Holzapfel, F. (2008). Predictor-Tunnel Display and Direct Force Control for Improving Flight Path Control. In: AIAA Guidance, Navigation and Control Conference and Exhibit, Guidance, Navigation, and Control and Co-located Conferences, 18-21 August 2008, Honolulu, Hawai, US, AIAA 2008-6644,

https://doi.org/10.2514/6.2008-6644
Sachs, G., Schuck, F., Holzapfel, F., Schaller, J. (2008). Improvement for Landing on Small-Medium Airports Using Future, Aircraft-Autonomous Guidance Aids. In: 26th Congress of International Council of Aeronautical Science. Anchorage, Alaska, USA, Sept. 14-19, 2008, pp. 11. http://www.icas.org/ICAS_ARCHIVE/ICAS2008/ABSTRACTS/459.HTM

Sachs, G., Moravszki, Cs. (2002). Simulation Experiments for Hypersonic Trajectory Control Using a Predictive Flight Path Display. In: AIAA Atmospheric Flight Mechanics Conference and Exhibit, Guidance, Navigation, and Control and Co-located Conferences. Monterey, California, US, 5-8 August 2002, AIAA 2002-4696, pp. 624-633. https://doi.org/10.2514/6.2002-4696

Sachs, G., Moravszki, Cs. (2006). Predictive Tunnel Display for Hypersonic Flight Path Control. In: AIAA Guidance, Navigation, and Control Conference and Exhibit. Keystone, Colorado, USA, Aug. 21-24, 2006, AIAA 2006-6562, https://doi.org/10.2514/6.2006-6562

Shish, K., Kaneshige, J., Acosta, D., Schuet, S., Lombaerts, T., Martin, L. Madavan, A. (2015). Trajectory Prediction and Alerting for Aircraft Mode and Energy State Awareness. In: AIAA 2015-1113, AIAA SciTech, Kissimmee, FL https://doi.org/10.2514/6.2015-1113

Szabolcsi, R. (2007). Stochastic Noises Affecting Dynamic Performances of the Automatic Flight Control Systems. Review of the Air Force Academy. 1(2009), pp. 23-30.

Szabolcsi, R. (2008). Handling Time Delay in Control of Unmaned Robots. Bolyai Szemle. 17(4), pp. 47-60.

http://portal.zmne.hu/download/bjkmk/bsz/bszemle2008/4/03_ Szabolcsi_Robert.pdf

Горбунов, А. Л., Нечаев, Е. Е. (2015). Мобильный комплекс дополненной реальности для управления воздушным судном, Вестник Концерна ПВО «Алмаз - Антей» 1, pp. 82-87. (in Russian) http://www.almaz-antey.ru/InFo-data/item_036/file_0002018.pdf 